\title{
BMJ Open Inhaled amikacin versus placebo to prevent ventilator-associated pneumonia: the AMIKINHAL double- blind multicentre randomised controlled trial protocol
}

Elsa Tavernier (1D , ${ }^{1}$ Francois Barbier, ${ }^{2}$ Ferhat Meziani, ${ }^{3}$ Jean-Pierre Quenot (D) , ${ }^{4}$ Jean-Etienne Herbrecht (1) , Mickael Landais (1) , ${ }^{5}$ Damien Roux (1) , ${ }^{7}$ Philippe Seguin, ${ }^{8}$ David Schnell (1) , ${ }^{9}$ Anne Veinstein, ${ }^{10}$ Benoît Veber, ${ }^{11}$ Sigismond Lasocki, ${ }^{12}$ Qin Lu, ${ }^{13}$ Gaetan Beduneau, ${ }^{14}$ Martine Ferrandiere (D) , ${ }^{15}$ Claire Dahyot-Fizelier, ${ }^{16}$ Gaetan Plantefeve, ${ }^{17}$ Mai-Anh Nay (DD , ${ }^{2}$ Hamid Merdji, ${ }^{3}$ Pascal Andreu, ${ }^{4}$ Laurent Vecellio, ${ }^{18}$ Grégoire Muller (1) , ${ }^{2}$ Maria Cabrera, ${ }^{18}$ Deborah Le Pennec, ${ }^{18}$ Renaud Respaud, ${ }^{19}$ Philippe Lanotte, ${ }^{20}$ Nicolas Gregoire, ${ }^{21}$ Marie Leclerc, ${ }^{22}$ Julie Helms, ${ }^{3}$ Thierry Boulain (D) , ${ }^{2}$ Jean-Claude Lacherade, ${ }^{23}$ Stephan Ehrmann (D), ${ }^{24}$ On behalf of the REVA network and the CRICSTRIGGESEP F-CRIN network

To cite: Tavernier E, Barbier F, Meziani F, et al. Inhaled amikacin versus placebo to prevent ventilator-associated pneumonia: the AMIKINHAL double-blind multicentre randomised controlled trial protocol. BMJ Open 2021;11:e048591. doi:10.1136/ bmjopen-2020-048591

\section{- Prepublication history for} this paper is available online. To view these files, please visit the journal online (http://dx.doi. org/10.1136/bmjopen-2020048591).

Received 05 January 2021 Accepted 25 August 2021

Check for updates

(C) Author(s) (or their employer(s)) 2021. Re-use permitted under CC BY-NC. No commercial re-use. See rights and permissions. Published by BMJ.

For numbered affiliations see end of article.

Correspondence to

Professor Stephan Ehrmann;

stephan.ehrmann@univ-tours.fr

\section{ABSTRACT}

Introduction Pre-emptive inhaled antibiotics may be effective to reduce the occurrence of ventilatorassociated pneumonia among critically ill patients. Meta-analysis of small sample size trials showed a favourable signal. Inhaled antibiotics are associated with a reduced emergence of antibiotic resistant bacteria. The aim of this trial is to evaluate the benefit of a 3-day course of inhaled antibiotics among patients undergoing invasive mechanical ventilation for more than 3 days on the occurrence of ventilator-associated pneumonia.

Methods and analysis Academic, investigatorinitiated, parallel two group arms, double-blind, multicentre superiority randomised controlled trial. Patients invasively ventilated more than 3 days will be randomised to receive $20 \mathrm{mg} / \mathrm{kg}$ inhaled amikacin daily for 3 days or inhaled placebo ( $0.9 \%$ Sodium Chloride). Occurrence of ventilator-associated pneumonia will be recorded based on a standardised diagnostic framework from randomisation to day 28 and adjudicated by a centralised blinded committee. Ethics and dissemination The protocol and amendments have been approved by the regional ethics review board and French competent authorities (Comité de protection des personnes Ouest I, No.2016-R29). All patients will be included after informed consent according to French law. Results will be disseminated in international scientific journals.

Trial registration numbers EudraCT 2016-001054-17 and NCT03149640.

\section{Strengths and limitations of this study}

- This is the first large scale multicentre study evaluating pre-emptive inhaled antibiotic therapy among critically ill patients at risk of ventilator-associated pneumonia.

- Mains strengths are the blinded randomised design and the sample size calculation based on current incidence of ventilator-associated pneumonia.

- The use of $0.9 \% \mathrm{NaCl}$ nebulisation, unavoidable to implement a blinded placebo arm represents a limitation as this may induce clinical effects per se.

- Diagnosis of ventilator-associated pneumonia, the primary outcome, may be considered subjective, however, the diagnostic workup has been standardised and a blinded adjudication committee implemented.

\section{INTRODUCTION}

\section{Background and rationale}

Ventilator-associated pneumonia (VAP) develops in about $5 \%-25 \%$ of intubated patients as a consequence of bacterial microaspirations leading to tracheobronchial colonisation, followed by lung parenchymal infection. ${ }^{1-4}$ This infectious process starts at intubation and occurs over several days. Whether the initial bacterial spread in the tracheobronchial tree has a significant impact on patients' outcome remains debated; however, once overt pneumonia 
occurs, a significant increase in morbidity and mortality is observed with a significant associated healthcare use cost. ${ }^{56}$ Thus, after a few days of mechanical ventilation, a therapeutic window of opportunity presents for stopping the infectious process before it impacts patients' outcome. $^{7}$ Several interventions limiting the tracheobronchial spread of bacteria, such as aspiration prevention, ${ }^{8}$ digestive and/or oral decontamination, ${ }^{9-15}$ and systemic antibiotics are effective to reduce the incidence of VAP. ${ }^{59}$ The major drawback of the latter is the risk of resistant bacteria selection. ${ }^{16}$ Indeed, receiving systemic antibiotics represents a risk factor for developing VAP due to antibiotic resistant bacteria. Conversely, inhaled antibiotic therapy presents several potential benefits: (1) very high tracheobronchial and pulmonary concentrations, far above the minimal concentration preventing resistance emergence, ${ }^{17}{ }^{18}$ (2) reduction of systemic exposure to antibiotics and ${ }^{19-21}$ (3) antibiotic deposition in the tracheal tube biofilm otherwise out of reach. ${ }^{22} 23$ Those benefits have been summarised in a meta-analysis showing a positive result of pooled data from five small sample size trials in favour of inhaled antibiotics to prevent hospital acquired pneumonia. ${ }^{24}$ Interestingly, as opposed to systemic delivery, inhaled antibiotics have repeatedly been associated with reduced emergence of resistant bacteria, some studies observing a reduced use of systemic antibiotics and thus associated selection pressure. ${ }^{21}{ }^{25}$ Our hypothesis is that a 3-day course of preemptive inhaled amikacin, delivered after 3 days of ventilation, will reduce the subsequent incidence of VAP. Our objective is to provide high level evidence in this regard in order to directly impact patient care to reduce the incidence of VAP and its related morbidity and mortality.

\section{Study objectives}

Primary objective: To prove that after the third day of invasive mechanical ventilation, a 3-day course of inhaled amikacin reduces the incidence of subsequent VAP.

Secondary objectives: To prove that after the third day of invasive mechanical ventilation a 3-day course of inhaled amikacin:

- Reduces the incidence of subsequent VAP in the subgroup of patients with significant tracheobronchial bacterial colonisation at randomisation.

- Reduces the incidence of subsequent VAP in the subgroup of patients with tracheobronchitis at randomisation.

- Reduces the incidence of subsequent VAP due to Gram negative bacteria susceptible to amikacin.

- Reduces clinical signs of tracheobronchial and lung infection.

- Reduces the incidence of ventilator-associated events.

- Reduces the subsequent use of systemic antibiotics.

- Speeds up weaning from mechanical ventilation.

- Reduces the length of stay in the intensive care unit (ICU) and in the hospital.

- Reduces the ICU, hospital, day-28 and day-90 mortality.
- Is not associated with an increased incidence of acute kidney injury (AKI).

To assess the impact of a 3-day course of inhaled amikacin on:

- The incidence of antibiotic-resistant bacteria nosocomial infection.

- The incidence of rectal carriage of antibiotic resistant bacteria.

To evaluate aerosol-related safety.

\section{METHODS AND ANALYSIS}

\section{Study setting and trial design}

The study is an academic, investigator-initiated multicentre parallel two group randomised controlled doubleblind superiority clinical trial assessing the efficacy of pre-emptive inhaled amikacin vs placebo on the incidence of VAP. Nineteen centres in France are participating in recruitment. All centres apply standard VAP preventive measures according to current guidelines.

\section{Patient and public involvement}

The study protocol development did not involve patients, nor were patients involved in recruitment and conduct of the study.

Results will be made available to study participants on request.

\section{Eligibility criteria}

Inclusion criteria

- Age $\geq 18$ years.

- Mechanical ventilation through an endotracheal tube for more than three consecutive days ( 72 hours).

- Written informed consent of the patient or a proxy.

- French social security coverage.

- Negative pregnancy test in women of childbearing potential.

Non-inclusion criteria

- Suspected or confirmed VAP the day of inclusion.

- Clinical indication for systemic aminoglycoside therapy the day of inclusion: as deemed necessary by the clinician in charge.

- Stage 2 or 3 Kidney Disease Improving Global Outcome (KDIGO) classification AKI the day of inclusion. ${ }^{26}$ Patients undergoing renal replacement therapy or for whom decision has been made to initiate renal replacement therapy can be included whatever the KDIGO stage.

- Chronic kidney failure with baseline glomerular filtration lower than $30 \mathrm{~mL} / \mathrm{min}$.

- Patient scheduled for extubation within the next 24 hours.

- Patient ventilated through an endotracheal tube for more than four consecutive days (96hours).

- Tracheostomy.

- Patients known to be allergic to aminoglycosides.

- Myasthenia gravis. 

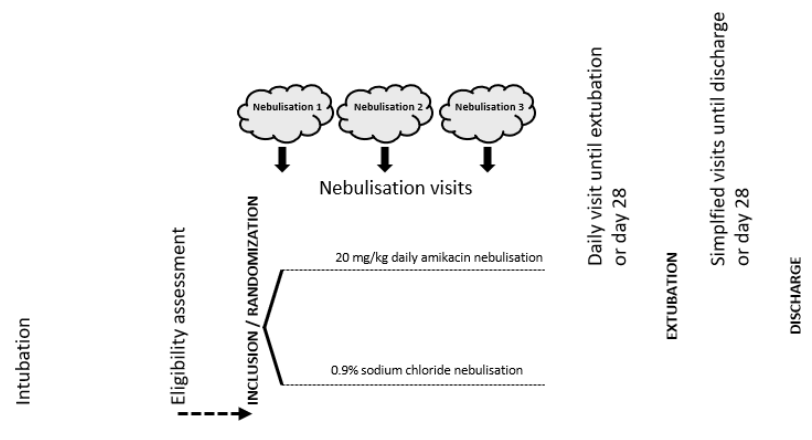

Days $1 \quad 2 \quad 3 \quad 4$

56

$\mathrm{X}$

Y

Figure 1 Study outline.

- Pregnant or breastfeeding women.

- Guardianship or trusteeship.

- Patients previously included in the study.

Patients with COVID-19 were eligible in the study.

\section{Intervention}

Figure 1 presents the study outline, interventions and data collection time points.

Experimental group

Sulfite-free amikacin powder (Merck génériques, Lyon, France) will be solubilised in sterile water $(1 \mathrm{~g}$ per $8 \mathrm{~mL})$ and used for nebulisation once a day during 3 days at a dose of $20 \mathrm{mg} / \mathrm{kg}$ based on predicted body weight, ${ }^{27}$ with a maximal dose of $2 \mathrm{~g}$.

\section{Control group}

A unit dose of saline solution of $0.9 \%$ sodium chloride $(\mathrm{NaCl})$ will be used as placebo. The equivalent volume of $0.9 \% \mathrm{NaCl}$ will be placed in the nebuliser and delivered once a day for 3 days.

\section{Nebulisation procedure}

Nebulisation will be performed in both randomisation groups, using a disposable vibrating mesh nebuliser: Aeroneb solo (Aerogen, Galway, Ireland). This nebuliser produces droplets compatible with drug lung deposition in the setting of invasive mechanical ventilation. ${ }^{21}$

The nebuliser will be placed upstream of the $\mathrm{Y}$ piece, a filter will be placed on the expiratory limb to protect the ventilator. Two types of circuits will be implemented: a dry circuit optimised for aerosol delivery (reference 2154019, Intersurgical, Wokingham, UK) or a standard active heated and humidified circuit (RT380, Fisher \& Paykel, Auckland, New Zeeland) with or without active humidification interruption during nebulisation. Ventilator settings, sedation and muscle relaxation during nebulisation will be left at the discretion of the attending physician. Ventilator mode and settings will not be changed for the purpose of the study, however, a standard operating procedure will be provided to all participating centres with a bedside checklist to ensure optimal nebulisation implementation in terms of safety and efficacy. ${ }^{28}$ Nebulisation will not be performed in case of extubation or patients meeting AKI exclusion criteria or requiring systemic aminoglycosides. In case of reintubation within the time frame of planed nebulisation, the latter will be performed.

All concomitant care and treatments are authorised during the study. Including systemic amikacin (intravenous or oral) delivery after the 3 days of study treatment or other inhaled antibiotics after the 3 days of study treatment. Measurement of amikacin serum concentration is forbidden up to 48 hours after the end of study treatment delivery. Post-trial care is left at the attending physician discretion.

\section{Blinding}

Blinding will be maintained throughout the trial. Blinding will concern: all the trial participants and their proxies, all care providers, all outcome assessors, investigators and the members of the adjudication committee. In each centre, staff not involved in patient care will be unblinded and prepare the study drug. The study drug will be charged in the nebuliser in such a way that makes it impossible to distinguish amikacin from $0.9 \% \mathrm{NaCl}$ and will be transferred to investigators and care providers for administration.

\section{Outcomes}

Primary outcome: Incidence of a first episode of VAP from randomisation to day 28.

Incidence will be calculated as the ratio of the number of patients experiencing a first VAP episode divided by the number of randomised patients. VAP definition will follow international guidelines ${ }^{29}$ : two criteria among the following: hyperleucocytosis ( $\geq 10000$ leucocytes $/ \mathrm{mm}^{3}$ ) or leucopenia $\left(\leq 4000\right.$ leucocytes $\left./ \mathrm{mm}^{3}\right)$ or fever $\left(\geq 38^{\circ} \mathrm{C}\right)$ or purulent secretion with a new chest X-ray infiltrate and significant quantitative bacterial culture in a pulmonary sample $\left(10^{5}, 10^{4}\right.$ or $10^{3}$ colony forming units per $\mathrm{mL}$ in a tracheal aspirate, bronchoalveolar lavage fluid or distal protected specimen, respectively). VAP diagnostic work up will be standardised between centres according to international guidelines (table 1).

Bacteriological lung specimen will be obtained, as much as possible at distance of any antibiotic administration, including nebulisation of study drug on relevant days.

\section{Secondary outcomes}

- Incidence of a first episode of VAP in the subgroup of patients with significant tracheobronchial bacterial colonisation at randomisation from randomisation to day 28 (tracheal aspirate, obtained after randomisation, positive at Gram-stain or growing $\geq 10^{5}$ colony forming units per $\mathrm{mL}$ at culture without clinical evidence for tracheobronchitis).

- Incidence of a first episode of VAP in the subgroup of patients with tracheobronchitis at randomisation from randomisation to day 28 (temperature $>38^{\circ} \mathrm{C}$ with no other cause, purulent tracheal secretions 
Table 1 Ventilator-associated pneumonia diagnostic workup

\begin{tabular}{|c|c|c|}
\hline Screening & Based on available routine data & $\begin{array}{l}\text { In case of new occurrence of any of the following : } \\
\text { Hyperleucocytosis }\left(\geq 10000 \text { leucocytes } / \mathrm{mm}^{3}\right) \text {. } \\
\text { Leucopenia }\left(\leq 4000 \text { leucocytes } / \mathrm{mm}^{3}\right) \text {. } \\
\text { Fever }\left(\geq 38^{\circ} \mathrm{C}\right) \text {. } \\
\text { Purulent secretion. } \\
\text { New chest X-ray infiltrate. } \\
\text { Significant respiratory compromise (decrease in PaO2/ } \\
\text { FiO2 ratio or increase in positive end-expiratory pressure). } \\
\text { Significant cardiovascular compromise (shock). } \\
\text { Move to VAP suspicion workup. }\end{array}$ \\
\hline VAP suspicion & $\begin{array}{l}\text { If not available obtain: } \\
\text { Complete white cell count. } \\
\text { Temperature measurement. } \\
\text { Semiquantitative and qualitative. secretion } \\
\text { assessment. } \\
\text { Chest X-ray. } \\
\text { Blood gases. }\end{array}$ & $\begin{array}{l}\text { In case of: } \\
\text { Definite or possible new chest X-ray infiltrate (or } \\
\text { significant respiratory or cardiovascular. compromise in } \\
\text { patients suffering ARDS*) and at least one among: } \\
\text { Hyperleucocytosis }\left(\geq 10000 \text { leucocytes } / \mathrm{mm}^{3}\right) \text { or } \\
\text { leucopenia }\left(\leq 4000 \text { leucocytes } / \mathrm{mm}^{3}\right) \text {. } \\
\text { Or } \\
\text { Or Fever }\left(\geq 38^{\circ} \mathrm{C}\right) \text {. } \\
\text { Move to possible VAP workup. }\end{array}$ \\
\hline Possible VAP & $\begin{array}{l}\text { Obtain bacteriological lung. specimen } \\
\text { (tracheal aspirate, bronchoalveolar lavage } \\
\text { or distal protected specimen). } \dagger \\
\end{array}$ & $\begin{array}{l}\text { Definite VAP diagnosis will be made a posteriori by an } \\
\text { adjudication committee based on possible VAP case report } \\
\text { form comprising clinical, microbiological data and original } \\
\text { chest X-rays. }\end{array}$ \\
\hline
\end{tabular}

*In patients suffering from the ARDS, chest X-ray interpretation for a new infiltrate may be difficult. Thus, VAP has to be considered in case of significant respiratory or cardiovascular compromise. In case of doubt consider VAP as possible.

†Bacteriological lung specimen will be obtained, as much as possible given local clinical and laboratory constraints, at distance of any antibiotic administration, including nebulisation of study drug on relevant days.

ARDS, acute respiratory distress syndrome; Fio2, fraction of inspired oxygen; PaO2, arterial oxygen tension; VAP, ventilator-associated pneumonia.

and a tracheal aspirate (obtained after randomisation) growing $\geq 10^{5}$ colony forming units per $\mathrm{mL}$ at culture $^{530}$ ).

- Incidence of VAP due to Gram negative bacteria sensitive to amikacin ${ }^{31}$ from randomisation to day 28.

- Clinical pulmonary infection score evolution after randomisation (score calculated daily based on available data from routine monitoring from randomisation to extubation or day 28 , whichever occurs first $\left.^{32-34}\right)$.

- Incidence of ventilator-associated events ${ }^{35}$ from randomisation to extubation or day 28, whichever occurs first.

- Number of systemic antibiotics administered per day from randomisation to day 28. Antibiotic*days will be computed summing the daily number of systemic antibiotics (intravenous and absorbable orally administered antibiotics).

- Number of days with at least one administration of a systemic antibiotic from randomisation to day 28.

- Number of days spent on invasive and non-invasive mechanical ventilation from randomisation to day 90 .

- Number of days from randomisation to the first successful spontaneous breathing trial.
- Number of days spent in the ICU and in the hospital after randomisation.

- ICU, hospital, day-28 and day-90 mortality.

- Incidence of antibiotic-resistant bacteria isolated on routine clinical and hygiene samples from randomisation to day 28. All bacteriological samples collected after randomisation will be recorded. The incidence of patients with samples growing bacteria resistant to amikacin otherwise naturally sensitive to amikacin and the incidence of multidrug-resistant, extensively drug-resistant and pandrug-resistant bacteria will be compared between groups. ${ }^{36}$

- Incidence of bacteria producing extended spectrum beta-lactamase or high level derepressed cephalosporinase, incidence of Enterococcus spp resistant to vancomycin on rectal samples at ICU discharge compared with randomisation in both groups.

- Incidence of AKI from randomisation to day 28. AKI will be defined according to the KDIGO classification. ${ }^{26}$ A priori defined exploratory outcomes:

- VAP suspicion by investigators filed to the adjudication committee from randomisation to day 28.

- VAP incidence density according to risk exposure from randomisation to day 28 . Incidence density will 
be calculated as the ratio of the number of patients experiencing a first VAP episode divided by the number of days of invasive mechanical ventilation received by randomised patients and expressed as the number of first VAP episodes per 1000 days of mechanical ventilation.

- Time between randomisation and the first episode of VAP in the subgroup of patients experiencing at least one VAP episode between randomisation and day 28.

- Primary and secondary outcome analyses in the subgroup of patients having received all three nebulisation (per-protocol analysis).

- Primary and secondary outcome analysis in the subgroup of patients extubated before the third nebulisation (patients who received one or two nebulisation).

- Primary and secondary outcome analyses in the subgroup of patients undergoing invasive mechanical ventilation for 7 days or more (first extubation occurring on day 8 or later).

- Primary and secondary outcome analysis according to the ventilatory circuit used for nebulisation (optimised dry circuit vs active heated humidified circuit vs interrupted heated humidification).

- Incidence of extubation failure (ie, reintubation or reintubation attempt within 7 days of extubation) from randomisation to day 28.

- Incidence of extubation failure (ie, reintubation or reintubation attempt within 7 days of extubation) in the subgroup of patients extubated within 7 days of randomisation.

- Cure of tracheobronchitis at day 10 in the subgroup of patients with tracheobronchitis at randomisation. Cure of tracheobronchitis will be defined as a temperature $<38^{\circ} \mathrm{C}$ and absent or rare tracheal secretions on semi-quantitative evaluation.

- Worsening of AKI defined as an increase in KDIGO classification stage (from stage 0 to stage 1 or from stage 1 to stage 2 or 3$).^{26}$

A priori defined ancillary analyses:

- Relative bacterial species composition of respiratory and digestive microbiota will be reported separately of the principal analysis. Relative amounts of bacteria composing the respiratory and digestive microbiota will be compared before and after amikacine or placebo inhalation in patients developing or not VAP. Microbiota analysis will rely on bacterial $16 \mathrm{~S}$ rDNA PCR amplification of the V3-V4 specific variable regions. The $460 \mathrm{bp}$ amplicons will be cleaned up using Agencourt Ampure XP SPRI beads (Beckman Coulter, Brea, California, USA) and quantified with Quant-iT dsDNA HS Assay Kit using Qubit fluorometer (Invitrogen, Carlsbad, California, USA). A second PCR will be then performed using the indexed oligos from Nextera XT kit (Illumina, San Diego, California, USA) to allow standardised sequencing with a MiSeq platform (Illumina). All bacterial sequence reads will be deposited for public access. Reads will be quality filtered using Quantitative Insights Into Microbial Ecology (QIIME) ${ }^{37}$ settings and then clustered into operational taxonomic units using a $97 \%$ sequence identity threshold using QIIME. ${ }^{37}$ Taxonomic levels will be determined using the RDP classifier with a confidence value of 0.5 considered as a positive identification. $^{38}$

- Sputum and serum amikacin pharmacokinetics will be reported separately of the principal analysis. Pharmacokinetic analysis will be carried out over the full duration of inhaled administration. 1-3 tracheal aspirates and 1-3 serum samples will be drawn per patient in the subsample of patients of centres participating to the pharmacokinetic study. To preserve blinding, samples will equally be taken in patients receiving amikacin or control. Samples will be frozen and analysed centrally at study end, after database locking, using a liquid chromatography combined with tandem mass spectrometry assay given the low systemic concentration to be expected. A total of 700 samples will be analysed, thus depending on recruitment among centres participating to the pharmacokinetic study, between 2 and 6 concentration measurements will be available for a subsample of 100-300 patients.

- Respiratory mechanics before and after nebulisation. Among sedated patients without spontaneous respiratory efforts an end expiratory and end inspiratory pause will be performed and resistance and compliance of the respiratory system will be calculated, immediately before and at the end of nebulisation as well as after 8, 12 and 24 hours.

\section{Sample size}

The following hypothesis is based on data of a previous trial of the CRICS-TriggerSEP research network and epidemiological surveillance data ${ }^{39}{ }^{40}$ :

- Incidence of first VAP episode of $12 \%$ in the control group.

- Incidence of first VAP episode of $6 \%$ in the experimental group.

Those hypotheses are conservative in terms of baseline VAP incidence and plan an important relative risk reduction which is deemed necessary to drive clinical practice change towards pre-emptive antibiotic inhalation in case of a positive trial. Indeed, a smaller risk reduction may be considered insufficient by the clinical community to implement large scale pre-emptive antibiotic therapy.

Sample size calculation took into consideration the competing risk of death occurring before extubation or VAP occurrence. ${ }^{41}$ Power was set at $80 \%$ and two-tailed type I error at a $5 \%$. A total number of 850 patients (425 in each arm) will be included in the trial.

\section{Recruitment}

All patients undergoing invasive mechanical ventilation through an endotracheal tube will be considered for inclusion and recorded on a screening log. Patients will be assessed for eligibility after 48 hours of invasive 
ventilation and included after 72 hours of invasive ventilation. Baseline data will be obtained, and randomisation performed the same day.

\section{Intervention allocation sequence}

Participants will be randomly assigned to either the control or experimental group with a 1:1 ratio allocation as per a computer-generated randomisation schedule stratified by centre and the administration of systemic antibiotics the day of randomisation (secured online system). The block sizes will not be disclosed to study investigators.

Allocation will not be disclosed to any person involved in patient care. Allocation sequence will be generated by a statistician not otherwise involved in recruitment or follow-up of the participants.

\section{Data collection, management and monitoring}

Nebulisation visits: nebulisation implementation and tolerance data will be recorded (table 2): ventilator settings, duration of nebulisation and occurrence of side effects. A check list will be provided.

Among centres and patients participating in the pharmacokinetic and microbiota prespecified ancillary analysis, tracheal aspirate, rectal and oral swabs as well as serum samples will be taken. Microbiota samples (oral and rectal swab, tracheal aspirate) will be taken before the first study drug delivery and after the third study drug delivery.

\section{Daily visits until extubation or day 28 whichever occurs first}

Those visits will be performed every day after inclusion, including on days of nebulisation as long as patients remain invasively ventilated.

Screening for VAP suspicion, signs of tracheobronchitis, clinical pulmonary infection score, ventilator-associated events, performance of a successful spontaneous breathing trial, administration of systemic antibiotics, all routine clinical bacteriological samples taken, AKI stage based on routine available data, and vital status will be recorded.

Among the patients participating in the microbiota ancillary analysis, a tracheal aspirate will be sampled for microbiota analyses on day 10 and day 13 (if still under invasive mechanical ventilation) and in case a first VAP episode occurs.

\section{Day 90 visit}

Vital status and day of discharge from the hospital and from ICU, and day of end of invasive and non-invasive mechanical ventilation will be recorded.

Adverse events will be recorded throughout the study. Independent data monitoring will be performed, independent trial audit will be performed if decided by the sponsor.

\section{Statistical methods}

The intention-to-treat principle will be applied. The number of participants with missing data for each variable of interest will be indicated. No interim analysis will be performed.
Descriptive analysis of patient groups at baseline

Baseline characteristics will be reported per group using descriptive statistics without statistical tests.

\section{Primary outcome analysis}

The incidence of VAP will be compared between the two groups using a competing risk analysis considering death as a competing event.

\section{Secondary outcome analysis}

- The following outcomes will be analysed in the framework of a competing risk analysis: incidence of VAP due to Gram-negative bacteria sensitive to amikacin, incidence of ventilator-associated events, number of days with at least one administration of a systemic antibiotic, number of days on invasive and non-invasive mechanical ventilation, number of days from randomisation to the first successful spontaneous breathing trial, ICU and hospital lengths of stay and mortality, incidence of resistant bacteria nosocomial infection and rectal carriage, incidence of AKI.

- The evolution of the clinical pulmonary infection score will be compared in the framework of a linear mixed model to take into account data correlation (several measures per patient).

- The day-28 and day-90 mortality will be analysed with a $\chi^{2}$ test.

\section{Predetermined subgroup analysis}

- The incidence of subsequent VAP in the subgroup of patients with significant tracheobronchial bacterial colonisation at randomisation will be compared in the framework of a competing risk analysis considering a term of interaction.

- The incidence of subsequent VAP in the subgroup of patients with tracheobronchitis at randomisation will be compared in the framework of a competing risk analysis considering a term of interaction.

\section{Exploratory analysis}

Analyses will be performed according to the same principals as the mains analysis (framework of competing risk analysis with death and/or extubation as a competing risk).

\section{Predetermined ancillary analyses}

- Microbiota analysis: bacterial taxonomic levels will be determined and clustering analysis will be carried out using UniFrac distance based principal coordinates analysis. ${ }^{42}$ Clustering analyses will be carried out using operational taxonomic units relative abundance based on read numbers as well as UniFrac distancebased principal coordinates analysis. Alpha diversity in the respiratory and digestive microbiota datasets will be calculated using both Shannon and phylogenetic diversity metrics.

- Pharmacokinetic analysis: tracheal aspirates and plasma concentrations (randomly distributed over the three sampling time frames: $0-6$ hours, $6-12$ hours 


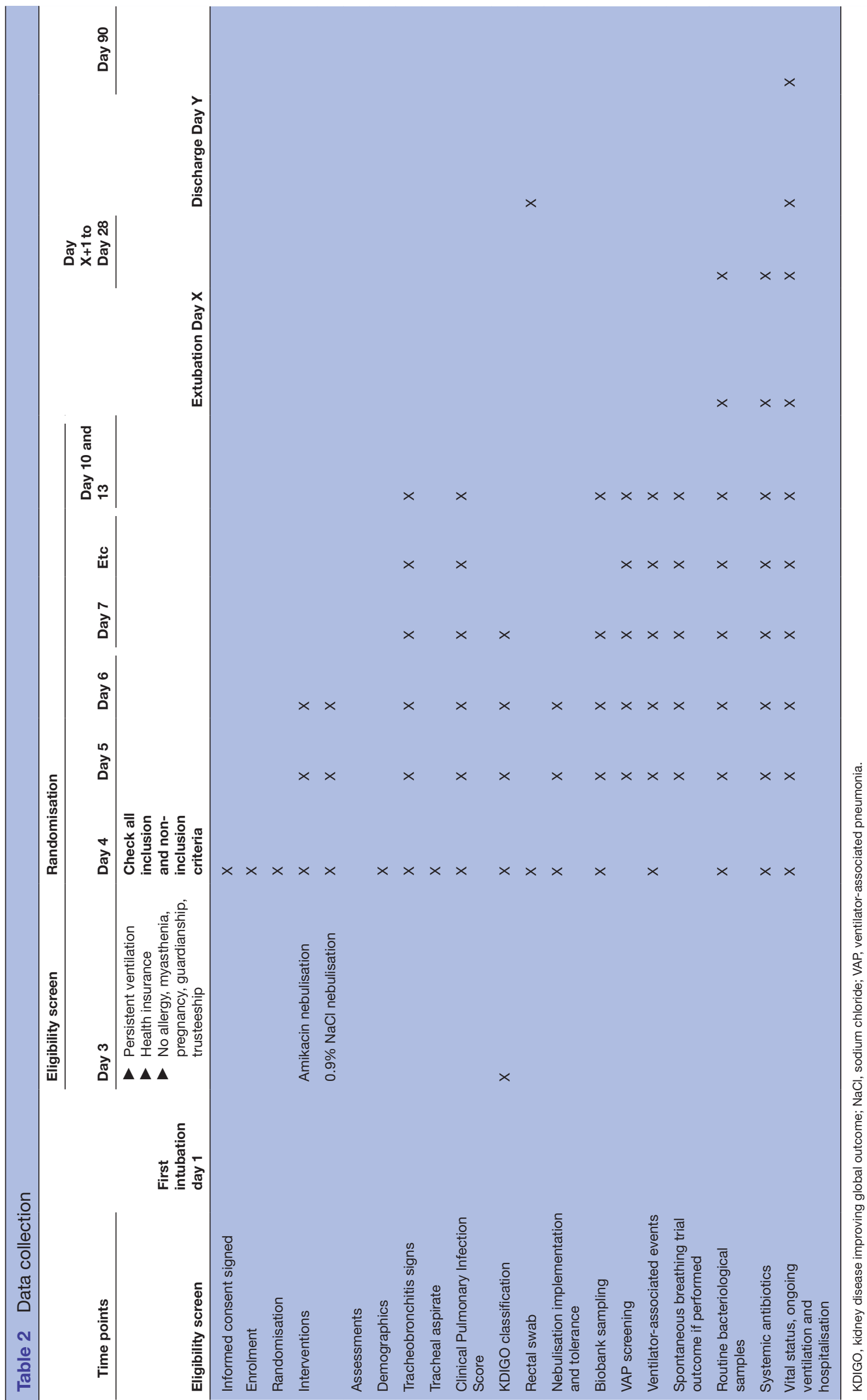


and 12-24 hours) will be analysed using a population pharmacokinetic approach with Nonmem7 (ICON Development solutions, Hanover, Maryland, USA), to determine amikacin exposure within aspirates and to investigate the relationships between its pharmacokinetic parameters and covariates. The population model will be adapted from previously published models. ${ }^{43}$ If appropriate pharmacokinetic parameters values estimated during the study will then be used for Monte Carlo simulations with the Berkeley Madonna software (V.8.3.18., University of California, Berkeley, California, USA) to estimate the probably of reaching the target for the relevant pharmacokineticpharmacodynamic index for efficacy and safety. Different nebulisation optimisation factors (circuit, humidification, ventilator settings, sedation) will be evaluated.

- Respiratory mechanics will be analysed comparing compliance and resistance of the respiratory system changes before and after nebulisation in study groups taking into account the paired nature of the data.

\section{Ethics and dissemination}

The study protocol and subsequent modifications were approved by the regional institutional review board (Comité de protection des personnes Ouest I, No.2016-R29) and national authorities (Agence nationale de sécurité des medicaments, No. 160821A-43).

\section{Informed consent}

Participants will be informed of the objectives of the study, including potential ancillary evaluation, and their informed consent will be obtained. In case patients are not able to be informed and give informed consent by themselves before study entry, information will be delivered to the legal representative if designated by the patient and informed consent obtained, otherwise, the information will be delivered and informed consent obtained from a patients proxy, eventually through telephone contact in the setting of COVID-19 pandemic visitors restrictions in accordance with institutional review board approval and French law. In all cases the patient will be informed and give written informed consent as soon as possible. Personal information will remain anonymous and managed according the current regulations.

\section{Dissemination policy}

Publication of the main results will mention the sponsor and the funding source. Publication will follow the recommendations for the conduct, reporting, editing and publication of scholarly work in medical journals from the international committee of medical journal editors. ${ }^{44}$ All investigators and persons involved in the study design and/or conduct not cited in the authorship will be listed as non-author contributors or acknowledgement within reasonable limits and editorial possibilities.

Authorship needs to achieve consensus. In case of disagreements, the principal coordinating investigator will decide on authorship. The first authors or last author will be the principal coordinating investigator. Other author places and order will be determined based on individual overall contribution to the study conception, design, conduct, analysis, interpretation and dissemination and include investigators of centres having included high numbers of patients with adequate data quality, scientific steering committee members, methodologist-data manager statistician, pharmacokinetic analyst, pharmacist; none of which is by itself sufficient for automatic authorship.

\section{Dissemination timeline}

The duration of patient enrolment expected is 4 years, starting in July 2017.

- End of 2015: national grant award.

- 2016: ethics and competent authority approval.

- 2017-2021: inclusion of patients; 805 out of 850 patients included the 14 December 2020.

- 2021: data monitoring and queries to investigators; blind review to determine protocol violation, cleaning and closure of the database.

- 2022: data analysis, writing of the manuscript and submission for publication.

\section{DISCUSSION}

The present multicentre study will provide high level evidence regarding the potential benefit or lack of benefit of pre-emptive inhaled amikacin therapy among critically ill patients at risk of developing VAP. The large sample size of the study planned to include 850 patients is based on estimates of VAP incidence which are relevant to the current clinical setting. Previous small sample size trials summarised in a meta-analysis in favour of the efficacy of pre-emptive inhaled antibiotics were performed in settings of very high VAP incidence and are therefore not relevant to current practice. ${ }^{24}$ The large sample size will also further document the feasibility and safety of antibiotic nebulisation among intubated patients completing data obtained during trials evaluating inhaled antibiotics to cure VAP. ${ }^{45}{ }^{46}$ Those studies failed to observe a benefit of inhaled antibiotics given as an adjunctive therapy to standard intravenous antibiotics in patients already suffering VAP. The present study, exploring patients in the days preceding the occurrence of overt VAP, that is, patients with no tracheobronchial bacterial spread, those with asymptomatic tracheobronchial colonisation, those with clinical tracheobronchitis will give important insight on the patient population most likely to benefit of inhaled antibiotics.

The control group of the present study may be discussed as to ensure adequate blinding of the placebo arm of the trial, $0.9 \% \mathrm{NaCl}$ was nebulised which may per se induced positive or negative clinical outcome. Indeed, nebulised $0.9 \% \mathrm{NaCl}$ is known to affect mucus rheological properties. Furthermore, no systemic antibiotics are delivered as part of the protocol in the control group, while patients may receive intravenous antibiotics to treat any type of infection other than VAP. Intravenous antibiotics given as part of some regimen of selective decontamination of 
the digestive tract are effective to prevent VAP occurrence and could have been protocolised in the control group. ${ }^{47}$ The present trial represents a pragmatic study evaluating the potential benefit of pre-emptive inhaled amikacin to decrease VAP occurrence.

\section{Author affiliations}

${ }^{1}$ Inserm CIC 1415, CHRU Tours, Tours, France

${ }^{2}$ Médecine Intensive Réanimation, CHR d'Orléans, Orleans, France

${ }^{3}$ Service de Réanimation, Nouvel Hôpital Civil, Université de Strasbourg (UNISTRA),

Faculté de Médecine, Hôpitaux universitaires de Strasbourg, Strasbourg, France

${ }^{4}$ Department of Intensive Care, Lipness Team, INSERM Research Centre LNCUMR1231, LabExLipSTIC, and INSERM CIC 1432, Clinical Epidemiology, François

Mitterrand University Hospital, University of Burgundy, Dijon, France

${ }^{5}$ Médecine Intensive Réanimation, Hôpital Hautepierre, Hôpitaux universitaires de Strasbourg, Strasbourg, France

${ }^{6}$ Réanimation médico-chirurgicale, $\mathrm{CH}$ du Mans, Le Mans, France

${ }^{7}$ Médecine Intensive Réanimation, Hôpital Louis Mourier, Assistance Publique -

Hopitaux de Paris, Colombes, France

${ }^{8}$ Réanimation Chirurgicale, CHU Rennes, Rennes, France

${ }^{9}$ Réanimation Polyvalente, CH Angouleme, Angouleme, France

${ }^{10}$ Médecine Intensive Réanimation, CHU de Poitiers, Poitiers, France

${ }^{11}$ Réanimation Chirurgicale, CHU de Rouen, Université de Rouen Normandie, Rouen, France

${ }^{12}$ Réanimation Chirurgicale, CHU Angers, Angers, France

${ }^{13}$ Multidisciplinary Critical Care Unit, Department of Anaesthesiology and Critical

Care Medicine, Pitié-Salpêtrière Hospital, Assistance Publique-Hôpitaux de Paris,

Sorbonne Université, Paris, France

${ }^{14}$ Medical Intensive Care Unit, EA 3830, Normandie Université, UNIROUEN, Rouen

University Hospital, Rouen, France

${ }^{15}$ Réanimation Chirurgicale, CHRU Tours, Tours, France

${ }^{16}$ Réanimation Chirurgicale, CHRU de Poitiers, Poitiers, France

${ }^{17}$ Réanimation Polyvalente et Unité de Surveillance Continue, CH Victor Dupouy, Argenteuil, France

${ }^{18}$ Centre d'Etude des Pathologies Respiratoires, CEPR, INSERM U1100, Faculté de médecine, Université de Tours, Tours, France

${ }^{19}$ Pharmacie, Centre d'Etude des Pathologies Respiratoires, CEPR, INSERM U1100, CHRU de Tours, Faculté de médecine, Université de Tours, Tours, France

${ }^{20}$ Service de Bactériologie-Virologie, INRAE, ISP, CHRU de Tours, Université de Tours, Tours, France

${ }^{21}$ INSERM UMR S1070, Laboratoire pharmacologie des anti-infectieux; Laboratoire de toxicologie-phamacologie, Université de Poitiers; CHU de Poitiers, Poitiers, France

${ }^{22}$ Délégation à la Recherche Clinique et à l'Innovation, CHRU Tours, Tours, France

${ }^{23}$ Médecine Intensive Réanimation, CHD de Vendée, La Roche-sur-Yon, France

${ }^{24}$ Médecine Intensive Réanimation, CIC 1415, Centre d'Etude des Pathologies Respiratoires, CEPR, INSERM U1100, CHRU de Tours, Faculté de médecine, Université de Tours, Tours, France

\section{Twitter Jean-Pierre Quenot @Quenot and Grégoire Muller @a6tole}

Acknowledgements The authors sincerely thank Grégory Reychler, David Grimaldi, Kada Klouche for serving in the data safety monitoring board.

Contributors SE, ET, J-CL, QL, FB and PL, in collaboration with the scientific board of the CRICS-Triggersep network and the study steering committee designed the study. ET provided substantial contribution to the conception and design of the study and wrote the statistical analysis plan and estimated the sample size with SE and J-CL. LV, DLP, MC and RR carried out in vitro analysis of the nebulisation set up and pharmacy logistical development of active treatment and placebo. SE drafted the manuscript. FB, FM, J-PQ, J-EH, MLa, DR, PS, DS, AV, BV, SL, QL, GB, MF, CD-F, GP, M-AN, HM, PA, GM, JH, TB, J-CL and SE include patients. MLe coordinated project management, study setup and quality control. All authors revised the manuscript critically for important intellectual content and approved the final version. All authors give their agreement to be accountable for all aspects of the work and ensure the accuracy and integrity of any part of the work. Scientific steering committee at study conception: Jean-Claude Lacherade, Olivier Mimoz, Pierre-François Dequin, FB, Claude Guerin, QL, Antoine Guillon, AV, René Robert, Frédéric Bellec, PL. Data safety monitoring board : Grégory Reychler, David Grimaldi, Kada Klouche.
Funding The study was funded by the 'Programme Hospitalier de Recherche Clinique National 2015' of the French Ministry of Health (grant number: PHRC-15260) and 'Association pour la promotion à Tours de la Réanimation Médicale' (grant number: not applicable). The study primary sponsor is the University Hospital of Tours, Tours, France (2, Bd Tonnellé. 37044 Tours cedex. France).

Competing interests SE declares consultancies from Aerogen, La Diffusion Technique Française; unrestricted research grants from Fisher \& Paykel Healthcare, Aerogen Ltd, Hamilton Medical; travel reimbursements from Aerogen and Fisher \& Paykel Healthcare.

Patient and public involvement Patients and/or the public were not involved in the design, or conduct, or reporting, or dissemination plans of this research.

Patient consent for publication Not required.

Provenance and peer review Not commissioned; externally peer reviewed.

Open access This is an open access article distributed in accordance with the Creative Commons Attribution Non Commercial (CC BY-NC 4.0) license, which permits others to distribute, remix, adapt, build upon this work non-commercially, and license their derivative works on different terms, provided the original work is properly cited, appropriate credit is given, any changes made indicated, and the use is non-commercial. See: http://creativecommons.org/licenses/by-nc/4.0/.

\section{ORCID iDs}

Elsa Tavernier http://orcid.org/0000-0003-0798-1182

Jean-Pierre Quenot http://orcid.org/0000-0003-2351-682X

Jean-Etienne Herbrecht http://orcid.org/0000-0002-6415-5330

Mickael Landais http://orcid.org/0000-0001-5320-4013

Damien Roux http://orcid.org/0000-0002-6103-6416

David Schnell http://orcid.org/0000-0003-3665-1385

Martine Ferrandiere http://orcid.org/0000-0003-2264-8230

Mai-Anh Nay http://orcid.org/0000-0002-6116-4987

Grégoire Muller http://orcid.org/0000-0002-9284-3560

Thierry Boulain http://orcid.org/0000-0003-4664-3661

Stephan Ehrmann http://orcid.org/0000-0001-6221-4467

\section{REFERENCES}

1 Torres A, Niederman MS, Chastre J, et al. International ERS/ESICM/ ESCMID/ALAT guidelines for the management of hospital-acquired pneumonia and ventilator-associated pneumonia: Guidelines for the management of hospital-acquired pneumonia (HAP)/ventilatorassociated pneumonia (VAP) of the European Respiratory Society (ERS), European Society of Intensive Care Medicine (ESICM), European Society of Clinical Microbiology and Infectious Diseases (ESCMID) and Asociación Latinoamericana del Tórax (ALAT). Eur Respir J 2017;50:1700582.

2 Kalil AC, Metersky ML, Klompas M, et al. Management of adults with hospital-acquired and ventilator-associated pneumonia: 2016 clinical practice guidelines by the infectious diseases Society of America and the American thoracic Society. Clin Infect Dis 2016;63:e61-111.

3 Koulenti D, Tsigou E, Rello J. Nosocomial pneumonia in 27 ICUs in Europe: perspectives from the EU-VAP/CAP study. Eur J Clin Microbiol Infect Dis 2017;36:1999-2006.

4 Papazian L, Klompas M, Luyt C-E. Ventilator-associated pneumonia in adults: a narrative review. Intensive Care Med 2020;46:888-906.

5 Nseir S, Martin-Loeches I, Makris D, et al. Impact of appropriate antimicrobial treatment on transition from ventilator-associated tracheobronchitis to ventilator-associated pneumonia. Crit Care 2014;18:R129.

6 Melsen WG, Rovers MM, Groenwold RHH, et al. Attributable mortality of ventilator-associated pneumonia: a meta-analysis of individual patient data from randomised prevention studies. Lancet Infect Dis 2013;13:665-71.

7 Schreiber PW, Sax H, Wolfensberger A, et al. The preventable proportion of healthcare-associated infections 2005-2016: systematic review and meta-analysis. Infect Control Hosp Epidemiol 2018;39:1277-95.

8 Pozuelo-Carrascosa DP, Herráiz-Adillo Ángel, Alvarez-Bueno C, et al. Subglottic secretion drainage for preventing ventilator-associated pneumonia: an overview of systematic reviews and an updated meta-analysis. Eur Respir Rev 2020;29:190107.

9 Wittekamp BHJ, Oostdijk EAN, Cuthbertson BH, et al. Selective decontamination of the digestive tract (SDD) in critically ill patients: a narrative review. Intensive Care Med 2020;46:343-9. 
10 de Smet AMGA, Kluytmans JAJW, Cooper BS, et al. Decontamination of the digestive tract and oropharynx in ICU patients. N Engl J Med 2009;360:20-31.

11 de Jonge E, Schultz MJ, Spanjaard L, et al. Effects of selective decontamination of digestive tract on mortality and acquisition of resistant bacteria in intensive care: a randomised controlled trial. Lancet 2003;362:1011-6.

12 Bergmans DC, Bonten MJ, Gaillard CA, et al. Prevention of ventilatorassociated pneumonia by oral decontamination: a prospective, randomized, double-blind, placebo-controlled study. Am J Respir Crit Care Med 2001;164:382-8.

13 Verwaest C, Verhaegen J, Ferdinande P, et al. Randomized, controlled trial of selective digestive decontamination in 600 mechanically ventilated patients in a multidisciplinary intensive care unit. Crit Care Med 1997;25:63-71.

14 Plantinga NL, de Smet AMGA, Oostdijk EAN, et al. Selective digestive and oropharyngeal decontamination in medical and surgical ICU patients: individual patient data meta-analysis. Clin Microbiol Infect 2018;24:505-13.

15 Plantinga NL, de Smet AMGA, Oostdijk EAN, et al. Selective digestive and oropharyngeal decontamination in medical and surgical ICU patients: individual patient data meta-analysis. Clin Microbiol Infect 2018:24:505-13.

16 Lim CLL, Chua AQ, Teo JQM, CLL L, JQM T, et al. Importance of control groups when delineating antibiotic use as a risk factor for carbapenem resistance, extreme-drug resistance, and pandrug resistance in Acinetobacter baumannii and Pseudomonas aeruginosa: a systematic review and meta-analysis. Int $J$ Infect Dis 2018:76:48-57.

17 Luyt C-E, Clavel M, Guntupalli K, et al. Pharmacokinetics and lung delivery of PDDS-aerosolized amikacin (NKTR-061) in intubated and mechanically ventilated patients with nosocomial pneumonia. Crit Care 2009;13:R200.

18 Niederman MS, Chastre J, Corkery K, et al. BAY41-6551 achieves bactericidal tracheal aspirate amikacin concentrations in mechanically ventilated patients with gram-negative pneumonia. Intensive Care Med 2012;38:263-71.

19 Petitcollin A, Dequin P-F, Darrouzain F, et al. Pharmacokinetics of high-dose nebulized amikacin in ventilated critically ill patients. $J$ Antimicrob Chemother 2016;71:3482-6.

20 Ehrmann S, Mercier E, Vecellio L, et al. Pharmacokinetics of highdose nebulized amikacin in mechanically ventilated healthy subjects. Intensive Care Med 2008;34:755-62.

21 Lu Q, Yang J, Liu Z, et al. Nebulized ceftazidime and amikacin in ventilator-associated pneumonia caused by Pseudomonas aeruginosa. Am J Respir Crit Care Med 2011;184:106-15.

22 Koerner RJ. Contribution of endotracheal tubes to the pathogenesis of ventilator-associated pneumonia. $J$ Hosp Infect 1997;35:83-9.

23 Mah TF, O'Toole GA. Mechanisms of biofilm resistance to antimicrobial agents. Trends Microbiol 2001;9:34-9.

24 Póvoa FCC, Cardinal-Fernandez P, Maia IS, et al. Effect of antibiotics administered via the respiratory tract in the prevention of ventilatorassociated pneumonia: a systematic review and meta-analysis. $J$ Crit Care 2018;43:240-5

25 Palmer LB, Smaldone GC. Reduction of bacterial resistance with inhaled antibiotics in the intensive care unit. Am J Respir Crit Care Med 2014;189:1225-33.

26 Kidney disease: improving global outcome. acute kidney injury work group KDIGO clinical practice guideline for acute kidney injury. Kidney Int 2012;2:S1-138.

27 Acute Respiratory Distress Syndrome Network, Brower RG, Matthay MA, et al. Ventilation with lower tidal volumes as compared with traditional tidal volumes for acute lung injury and the acute respiratory distress syndrome. N Engl J Med 2000;342:1301-8.

28 Ehrmann S, Chastre J, Diot P, et al. Nebulized antibiotics in mechanically ventilated patients: a challenge for translational research from technology to clinical care. Ann Intensive Care 2017;7:78.

29 American Thoracic Society, Infectious Diseases Society of America. Guidelines for the management of adults with hospital-acquired, ventilator-associated, and healthcare-associated pneumonia. Am J Respir Crit Care Med 2005;171:388-416.

30 Nseir S, Di Pompeo C, Pronnier P, et al. Nosocomial tracheobronchitis in mechanically ventilated patients: incidence, aetiology and outcome. Eur Respir J 2002;20:1483-9.

31 EUCAST. The European Committee on antimicrobial susceptibility testing. breakpoint table v5.0, 2015. Available: www.eucast.org/ clinical_breakpoints/

32 Fartoukh M, Maitre B, Honoré S, et al. Diagnosing pneumonia during mechanical ventilation: the clinical pulmonary infection score revisited. Am J Respir Crit Care Med 2003;168:173-9.

33 Pugin J, Auckenthaler R, Mili N, et al. Diagnosis of ventilatorassociated pneumonia by bacteriologic analysis of bronchoscopic and nonbronchoscopic "blind" bronchoalveolar lavage fluid. Am Rev Respir Dis 1991;143:1121-9.

34 Singh N, Rogers P, Atwood CW, et al. Short-Course empiric antibiotic therapy for patients with pulmonary infiltrates in the intensive care unit. Am J Respir Crit Care Med 2000;162:505-11.

35 Centre for disease control. Surveillance for ventilator-associated events, 2015. Available: www.cdc.gov/nhsn/acute-care-hospital/vae/

36 Magiorakos A-P, Srinivasan A, Carey RB, et al. Multidrug-resistant, extensively drug-resistant and pandrug-resistant bacteria: an international expert proposal for interim standard definitions for acquired resistance. Clin Microbiol Infect 2012;18:268-81.

37 QIIME. Quantitative insights into microbial ecology, 2020. Available: http://qiime.org/

38 RD pipeline. Center for microbial ecology. Michigan university, 2020. Available: https://pyro.cme.msu.edu/login.spr

39 Reignier J, Mercier E, Le Gouge A, et al. Effect of not monitoring residual gastric volume on risk of ventilator-associated pneumonia in adults receiving mechanical ventilation and early enteral feeding: a randomized controlled trial. JAMA 2013;309:249-56.

40 Surveillance des infections nosocomiales en réanimation adulte. Réseau REA-Raisin, France, résultats 2013, 2013. Available: https://www.santepubliquefrance.fr/maladies-et-traumatismes/ infections-associees-aux-soins-et-resistance-aux-antibiotiques/ infections-associees-aux-soins/documents/rapport-synthese/ surveillance-des-infections-nosocomiales-en-reanimation-adulte.reseau-rea-raisin-france-resultats-2013

41 Schulgen G, Olschewski M, Krane V, et al. Sample sizes for clinical trials with time-to-event endpoints and competing risks. Contemp Clin Trials 2005;26:386-96.

42 Lozupone C, Lladser ME, Knights D, et al. UniFrac: an effective distance metric for microbial community comparison. Isme $\mathrm{J}$ 2011;5:169-72.

43 Boisson M, Jacobs M, Grégoire N, et al. Comparison of intrapulmonary and systemic pharmacokinetics of colistin methanesulfonate (CMS) and colistin after aerosol delivery and intravenous administration of CMS in critically ill patients. Antimicrob Agents Chemother 2014;58:7331-9.

44 ICMJE. International Committee of medical journal editors, 2020. Available: http://www.icmje.org/

45 Niederman MS, Alder J, Bassetti M, et al. Inhaled amikacin adjunctive to intravenous standard-of-care antibiotics in mechanically ventilated patients with gram-negative pneumonia (inhale): a double-blind, randomised, placebo-controlled, phase 3, superiority trial. Lancet Infect Dis 2020;20:330-40.

46 Kollef $\mathrm{MH}$, Ricard J-D, Roux D, et al. A randomized trial of the amikacin fosfomycin inhalation system for the adjunctive therapy of gram-negative ventilator-associated pneumonia: IASIS trial. Chest 2017;151:1239-46.

47 Wittekamp BHJ, Oostdijk EAN, Cuthbertson BH, et al. Selective decontamination of the digestive tract (SDD) in critically ill patients: a narrative review. Intensive Care Med 2020;46:343-9. 